\title{
The management of elderly patients with lung cancer: a single center retrospective study
}

\author{
Ping Wang ${ }^{1 \#}$, Chunyan $\mathrm{Li}^{2 *}$, Yang An ${ }^{1 \#}$, Xiaoqian Wang ${ }^{2}$, Zhixin Liang ${ }^{1}$, Liang'an Chen ${ }^{1}$ \\ ${ }^{1}$ Department of Respiratory and Critical Care Medicine, the Eighth Medical Center of PLA General Hospital, Beijing, China; ${ }^{2}$ Department of \\ Respiratory and Critical Care Medicine, the First Medical Center of PLA General Hospital, Beijing, China \\ Contributions: (I) Conception and design: L Chen; (II) Administrative support: Z Liang; (III) Provision of study materials or patients: P Wang, Y An; \\ (IV) Collection and assembly of data: C Li, X Wang; (V) Data analysis and interpretation: P Wang; (VI) Manuscript writing: All authors; (VII) Final \\ approval of manuscript: All authors. \\ "These authors contributed equally to this work. \\ Correspondence to: Liang'an Chen. Department of Respiratory and Critical Care Medicine, the Eighth Medical Center of PLA General Hospital, \\ Beijing, China. Email: chenla301@263.net.
}

Background: The incidence of lung cancer in patients aged over 80 years accounts for $30 \%$ of the entire lung cancer population. However, the emphasis on the treatment and prognosis of this subpopulation remains poorly investigated. This study evaluated outcomes associated with treatment strategies for these patients.

Methods: A retrospective analysis was performed on the overall survival and treatment of deceased patients over 80 years of age, diagnosed with lung cancer in our hospital. Treatment and overall survival were evaluated using logistic regression, the Kaplan-Meier method, and multivariable Cox proportional hazard models.

Results: A total of 56 patients were included in this study, with 30 (53.6\%) patients diagnosed with stage IV at the time of detection. One-third of the patients refused any form of treatment. The majority $(\mathrm{n}=27,48.2 \%)$ of the included patients with stage I-IV lung cancer received chemotherapy or tyrosine kinase inhibitors (TKIs). The median overall survival was determined to be $9.067 \pm 1.2477$ months, with the median survival time of small cell lung cancer (SCLC) patients calculated as $7.167 \pm 3.797$ months for the entire cohort. The majority of patients exhibited lesions in the left upper lung and displayed the longest overall survival. For the over 80 yrs with lunch cancer patients, that who chose not to receive any treatment exhibited a shorter overall survival than those who received treatment.

Conclusions: Most patients in this study presented with advanced disease. Treatment-naïve patients exhibited a poorer prognosis compared to their counterparts who received treatment, highlighting the need for this subpopulation to access further treatment.

Keywords: Lung cancer; elder; patient; therapy

Submitted Sep 24, 2020. Accepted for publication Dec 23, 2020.

doi: 10.21037/apm-20-2125

View this article at: http://dx.doi.org/10.21037/apm-20-2125

\section{Introduction}

Lung cancer is ranked as the leading cause of cancer mortality among malignant tumors (1). In China, lung cancer was the third leading cause of years of life lost in 2017, exceeding chronic obstructive pulmonary disease, another common respiratory disease (2). However, the focus on the treatment and prognosis of lung cancer patients in people over 80 years of age is still poorly investigated, resulting in limited treatment options for this subpopulation. Our study collected the clinical data 
of lung cancer patients who expired in our hospital from 1998 to 2020, to evaluate the therapeutic significance and influencing factors of these patients. The study was intended to provide recommendations for clinicians regarding the treatment options available for lung cancer patients aged 80 years and older.

We present the following article in accordance with the STROBE reporting checklist (available at http://dx.doi. org/10.21037/apm-20-2125).

\section{Methods}

\section{Subjects}

The study was approved by the PLA General Hospital Medical Ethics Committee (S2020-447-01). All procedures performed in this study involving human participants were in accordance with the Declaration of Helsinki (as revised in 2013). Individual consent for this retrospective analysis was waived. Demographic and treatment information from 1998 to 2020 of deceased patients aged 80 years and older diagnosed with lung cancer were retrospectively collected in our hospital. Pathology was confirmed by histopathology and cytopathology. Patients without pathological confirmation were excluded. All patients were re-staged according to the International Association for the Study of Lung Cancer's (IASLC) TNM classification of lung cancer (8th edition) (3).

We first evaluated the overall cohort of patients aged 80 years and older with clinical stages I to IV lung cancer [non-small cell lung cancer (NSCLC) + small cell lung cancer (SCLC)], including staging and histology. Predictors of survival were determined using a multivariable logistic regression model. The variables in this adjusted model were age, sex, smoking, comorbidity condition, and history of previous malignancy.

Overall survival of the different subgroups (stages I-IV) stratified by treatment types (i.e., chemotherapy, or tyrosine kinase inhibitor (TKI), radiation, chemoradiation, surgery, and no treatment) was assessed using the Kaplan-Meier analysis and multivariable Cox models adjusting for clinical stage, tumor location, and histology.

\section{Statistical analysis}

For all comparisons, a $\mathrm{P}$ value $=0.05$ was used to define statistical significance. Statistical analysis was performed using SPSS software, version 25.0 (IBM).

\section{Results}

\section{Patient cobort}

From 1998 to 2020, 56 patients with lung cancer were enrolled into our study. These patients had died past 80 years of age, and had complete, clinically relevant data. Lung cancer was confirmed by pathology (histopathology and cytopathology), 7 patients exhibited SCLC, and 49 had NSCLC. Adenocarcinoma was the most common pathological type. Table 1 provides additional patient characteristics. In our patient cohort, most patients displayed concurrent diseases of other systems. The most common comorbidities were hypertension and coronary heart disease. Seven patients were identified to concurrently exhibit tumors in other systems. Approximately $40 \%$ of patients had an Eastern Cooperative Oncology Group (ECOG) score of 2 points and above at the time of diagnosis.

\section{Clinical characteristics and survival}

The overall median survival time in the subject population was $9.067 \pm 1.2477$ months. The median survival time of SCLC patients was $7.167 \pm 3.797$ months, whereas NSCLC cancer patients displayed an overall survival of $9.500 \pm 1.493$ months. The intergroup differences were not found to be significant (Figure 1 and Table 2). The effects of age and gender on the overall survival of patients were also not significant. However, smoking was shown to be a risk factor affecting the overall survival of patients $(\mathrm{P}<0.05)$ (Table 3). The effect of complications on patient survival was not significant.

\section{Primary tumor characteristics and survival}

In the study population, the left upper lung was the most affected site of lung cancer. Furthermore, the primary site of lung cancer significantly affected overall survival. Patients with the primary site at the left upper lung displayed the longest median survival time (Figure 2). Within our cohort, $76.8 \%$ of patients were not tested for driver gene mutations, only 2 patients exhibited epidermal growth factor receptor (EGFR) mutations, 1 displayed the v-raf murine sarcoma viral oncogene homologue B1 (BRAF) mutations, while another had receptor tyrosine kinase rearranged during transfection (RET) mutations. Furthermore, 9 had no mutations detected (Table 1). 
Table 1 Baseline patient characteristics

\begin{tabular}{|c|c|}
\hline Patient characteristics & $N=56$ \\
\hline Age (years) & $80-90(83.93 \pm 2.64)$ \\
\hline \multicolumn{2}{|l|}{ Sex, n (\%) } \\
\hline Male & $40(71.4)$ \\
\hline Female & $16(28.6)$ \\
\hline \multicolumn{2}{|l|}{ Smoking, n (\%) } \\
\hline Yes & $31(55.4)$ \\
\hline No & $25(44.6)$ \\
\hline \multicolumn{2}{|l|}{ ECOG PS, n (\%) } \\
\hline 0 & 0 \\
\hline 1 & $34(60.7)$ \\
\hline 2 & $17(30.3)$ \\
\hline 3 & $5(9)$ \\
\hline \multicolumn{2}{|l|}{ Histology, n (\%) } \\
\hline Adenocarcinoma & $31(55.4)$ \\
\hline $\mathrm{SqC}$ & $13(23.2)$ \\
\hline NSCLC-NOS & $5(8.9)$ \\
\hline SCLC & 7 (12.5) \\
\hline \multicolumn{2}{|l|}{ Cancer stage, n (\%) } \\
\hline IV & $30(53.6)$ \\
\hline III & $1(1.8)$ \\
\hline II & 0 \\
\hline I & $6(10.7)$ \\
\hline Unknown & $19(33.9)$ \\
\hline \multicolumn{2}{|l|}{ Comorbidity, n (\%) } \\
\hline Heart & $38(67.9)$ \\
\hline Lung & 19 (33.9) \\
\hline Diabetes & $9(16.1)$ \\
\hline Mental disorder & $10(17.9)$ \\
\hline Connective tissue disease & $1(1.8)$ \\
\hline Mild liver disease & $3(5.4)$ \\
\hline Any prior tumor & 7 (12.5) \\
\hline No & $5(8.9)$ \\
\hline \multicolumn{2}{|l|}{ Primary treatment, $\mathrm{n}(\%)$} \\
\hline Chemotherapy/TKI & $27(48.2)$ \\
\hline Radiation $(\mathrm{R}, \mathrm{R}+\mathrm{C})$ & $9(16.1)$ \\
\hline
\end{tabular}

Table 1 (continued)
Table 1 (continued)

\begin{tabular}{lc}
\hline Patient characteristics & $\mathrm{N}=56$ \\
\hline Surgery $(\mathrm{S}, \mathrm{S}+\mathrm{C}, \mathrm{S}+\mathrm{CR})$ & $4(7.1)$ \\
No & $16(28.6)$ \\
Tumor size, $\mathrm{n}(\%)$ & $10(17.9)$ \\
$\leq 30 \mathrm{~mm}$ & $7(12.5)$ \\
$\leq 50 \mathrm{~mm}$ & $7(12.5)$ \\
$>50$ mm & $32(57.1)$ \\
Unknown & \\
EGFR/other mutation, $\mathrm{n}(\%)$ & $2(3.6)$ \\
EGFR mutation & $9(16.1)$ \\
EGFR wild type & $1(1.8)$ \\
BRAF mutation & $1(1.8)$ \\
RET mutation & $43(76.8)$ \\
Not done & $9.500 \pm 1.493$ \\
Median survival for NSCLC, months & $7.167 \pm 3.797$ \\
Median survival for SCLC, months & \\
\hline
\end{tabular}

TKI, tyrosine kinase inhibitors; SqC, squamous carcinoma; NSCLC-NOS, non-small cell lung cancer not otherwise specified; NSCLC, non-small cell lung cancer; SCLC, small cell lung cancer; C, chemotherapy; R, radiation; S, surgery; EGFR, epidermal growth factor receptor; BRAF, v-raf murine sarcoma viral oncogene homologue $\mathrm{B} 1$; RET, rearranged during transfection.

\section{Treatment and survival}

In the overall study population, 16 patients did not receive any treatment after diagnosis confirmation. The most common treatment was chemotherapy. Four patients underwent surgical treatment, while 9 received radiation and chemoradiation. Meanwhile, 16 of the 56 patients aged 80 years or older with stage I-IV NSCLC did not receive any therapy. Survival analysis revealed a significantly worse survival rate for patients who did not receive any treatment, compared to their treated counterparts. The patients who underwent surgery displayed the longest survival duration (Figure 3).

\section{Staging and survival}

The effects of staging on patient survival are illustrated in Figure 4. In the overall population, $53.6 \%$ of patients were at stage IV at the time of diagnosis. Additionally, 33.9\% 


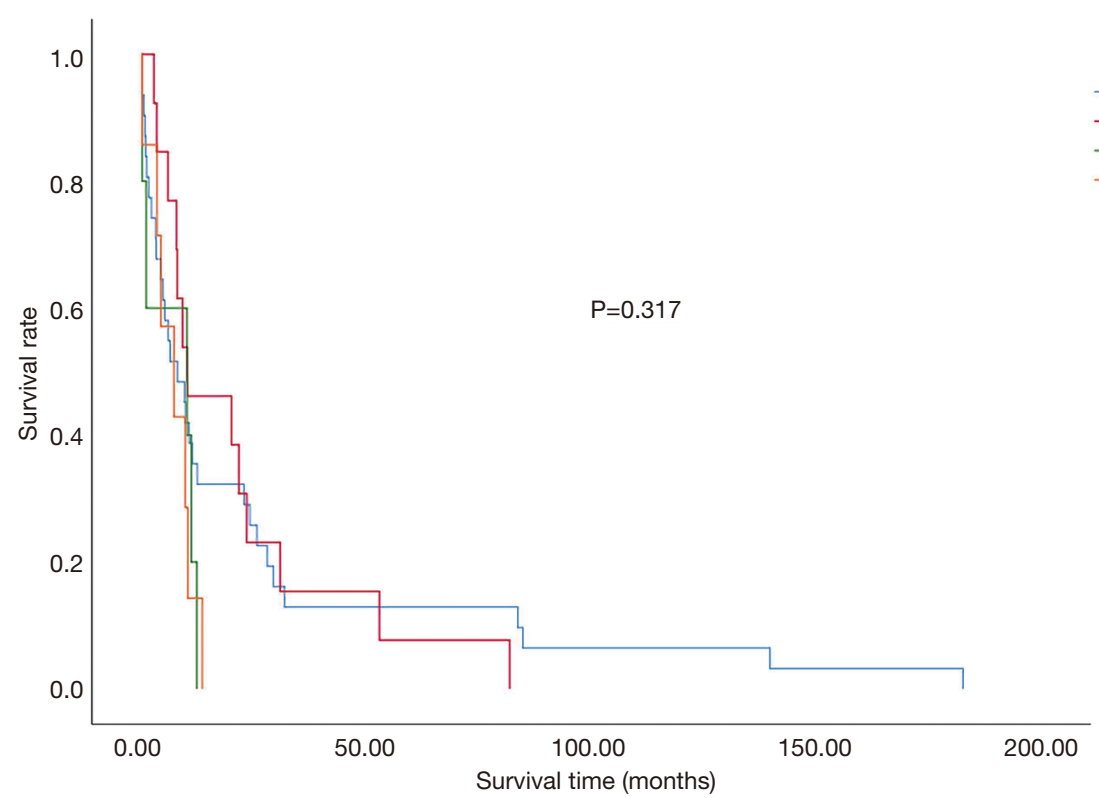

Figure 1 Histology and survival.

Table 2 Pathology and survival

\begin{tabular}{|c|c|c|c|c|}
\hline \multirow{2}{*}{ Pathology } & \multicolumn{4}{|c|}{ Median survival times } \\
\hline & Estimate & Std. error & Lower bound & Upper bound \\
\hline Adenocarcinoma & 7.967 & 2.541 & 2.986 & 12.948 \\
\hline $\mathrm{SqC}$ & 10.133 & 7.210 & 0.000 & 24.264 \\
\hline NSCLC-overall & 9.500 & 1.493 & 6.574 & 12.426 \\
\hline SCLC & 7.167 & 3.797 & 0.000 & 14.609 \\
\hline Overall & 9.067 & 1.247 & 6.622 & 11.511 \\
\hline
\end{tabular}

SqC, squamous carcinoma; NSCLC-NOS, not small cell lung cancer not otherwise specified; SCLC, small cell lung cancer.

of the total analysed population refused any examination to assess their condition (Table 1 and Figure 4). There was a significant correlation between progression-free survival (PFS) and overall survival. Both PFS1 obtained after the first treatment and PFS2 obtained after progression were significantly associated with survival time. However, no correlation was noted between the diagnosis-and-treatment interval and overall survival (Figure 5).

\section{Conclusions}

In the present study, the clinical data, treatment and survival time of 56 deceased patients with lung cancer diagnosed at our center were analyzed. Approximately one-third of patients refused tumor assessment and one-third refused treatment. An increased ECOG score, increased TNM stage, and concern for treatment side effects were the main factors for their refusal for treatment and examination. However, our study still included more treated patients compared to other investigations (4). After rigorous review, we concluded that this difference may be attributed to the development of targeted drugs with lower toxicity, which was more easily accepted by vulnerable, elderly patients. EGFR gene mutations were detected in only 2 patients, and 
Table 3 Clinical characteristics and survival

\begin{tabular}{|c|c|c|c|c|}
\hline Characteristics & $\mathrm{P}$ & OR & \multicolumn{2}{|c|}{$95.0 \% \mathrm{Cl}$ for $\operatorname{Exp}(\mathrm{B})$} \\
\hline Gender & 0.978 & 0.988 & 0.427 & 2.289 \\
\hline Smoking & 0.048 & 0.480 & 0.232 & 0.994 \\
\hline ECOG & 0.008 & & & \\
\hline ECOG [1] & 0.002 & 0.161 & 0.050 & 0.523 \\
\hline ECOG [2] & 0.038 & 0.255 & 0.070 & 0.924 \\
\hline Age & 0.487 & 0.962 & 0.864 & 1.072 \\
\hline
\end{tabular}

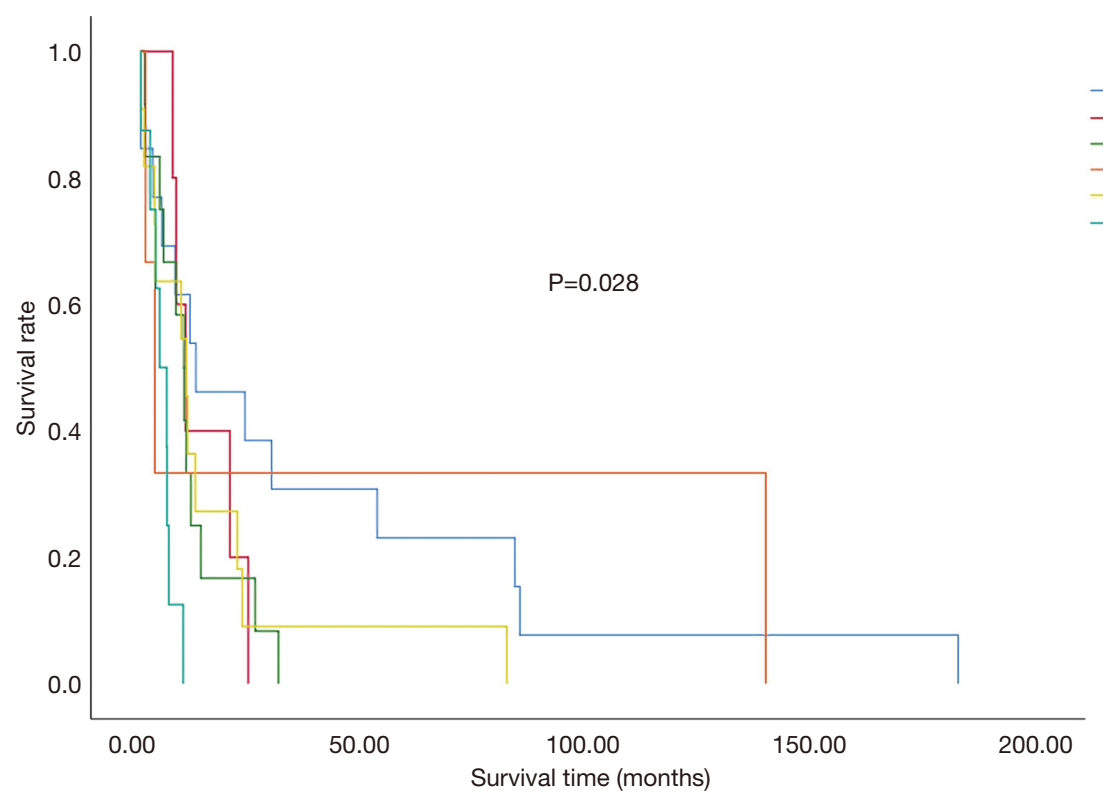

Figure 2 Primary tumor characteristics and survival.

were treated with EGFR-TKI therapy. Another 15 patients received the same treatment without gaining clear benefit. One of the limitations of the present is the small sample size, which affected the conclusion.

Our findings indicate that overall survival of treated patients exceeded that of their treatment-naïve counterparts. However, patients who received surgical removal at stage I predominantly benefited most, which was consistent with other studies $(5,6)$. Since economic evaluation was not performed, benefit from treatment in patients with high ECOG scores and advanced TNM stages remains to be determined for future investigations.

The gradual increase in the average age of lung cancer patients, along with the growing proportion of people aged over 80 years in this population highlights the need for further evaluations into the treatment options of this group. At present, an increasing number of studies have analyzed the therapeutic effect of these patients; however, the majority of these studies were retrospective (7-9). Reports of prospective clinical drug trials, solely targeting this population are still limited (10). Furthermore, the number of clinical studies that included this population is low $(11,12)$. 


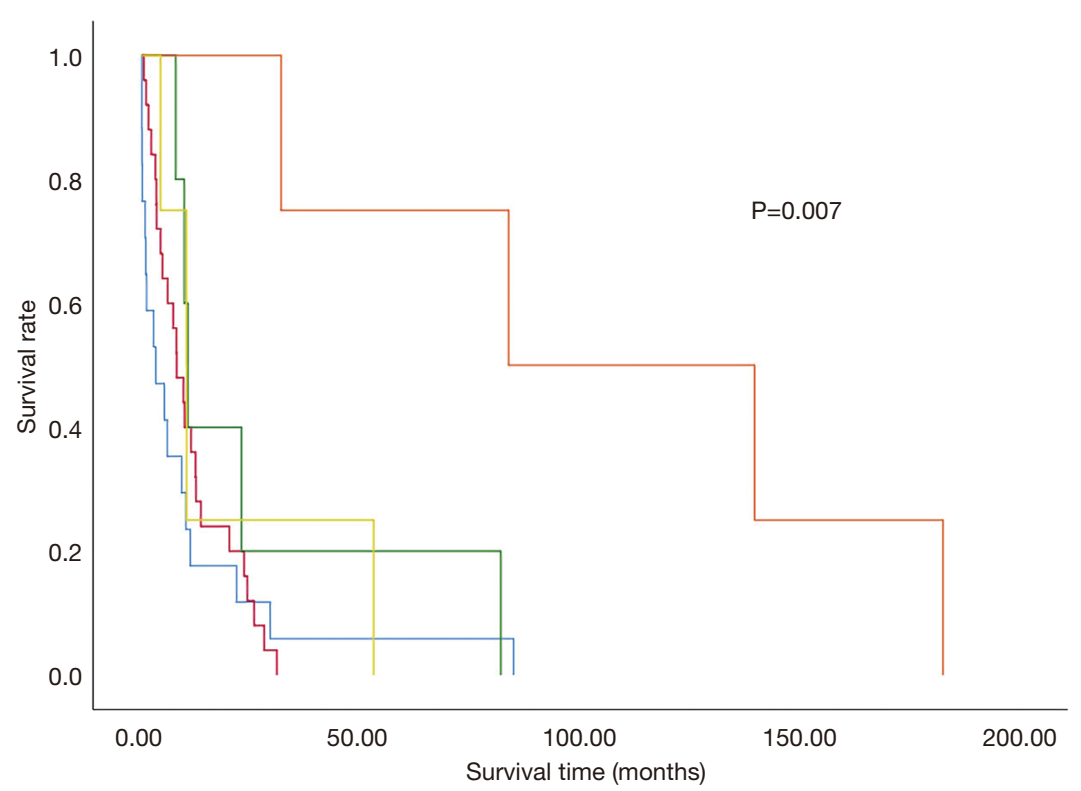

Figure 3 Treatment and survival.

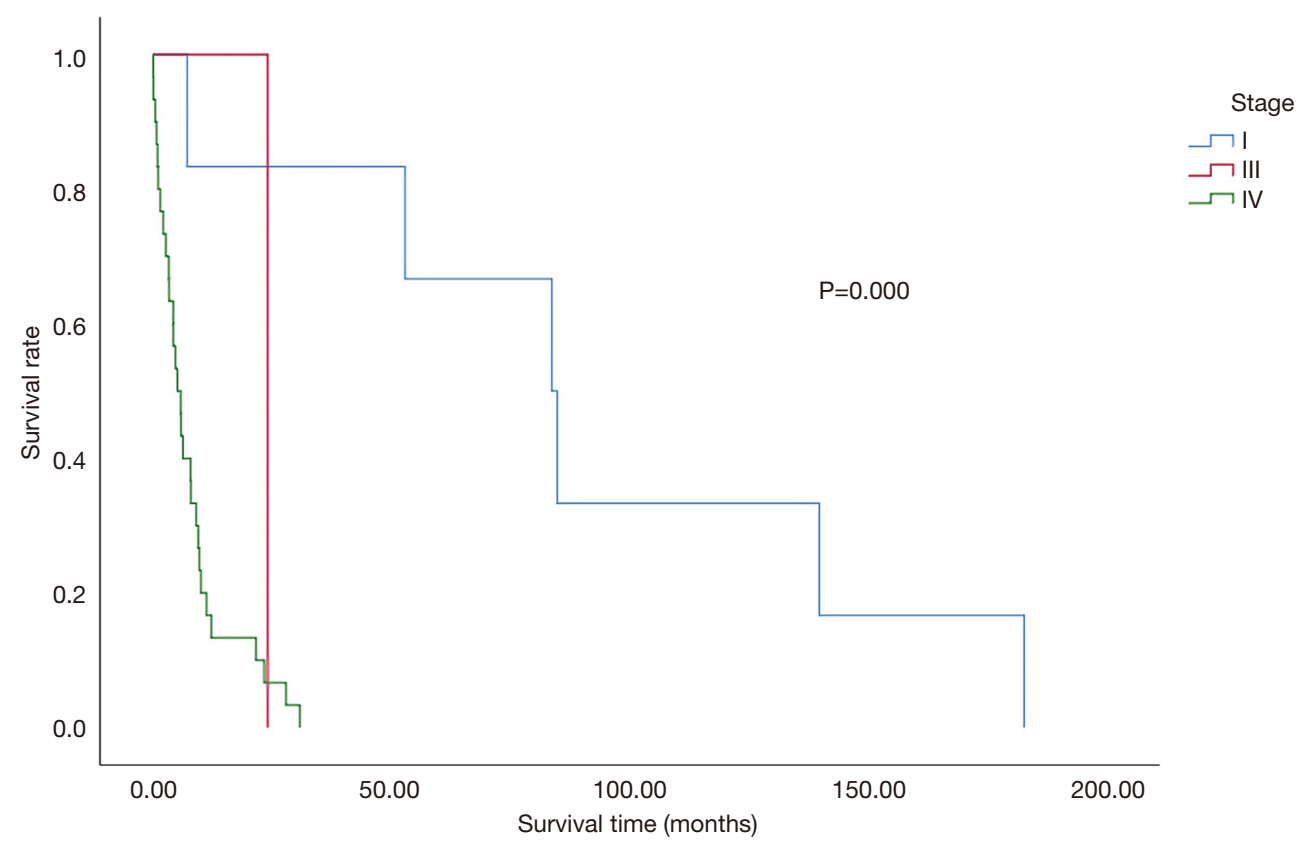

Figure 4 Stage and survival.

Further studies are expected to evaluate the treatment and prognosis of octogenarians.

The present study retrospectively evaluated the current status of treatment in lung cancer patients, aged 80 years and older. To minimize bias, we selected data from deceased patients. Due to the retrospective nature of the study, the

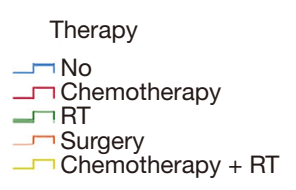

$\square$ Chemotherapy + RT 

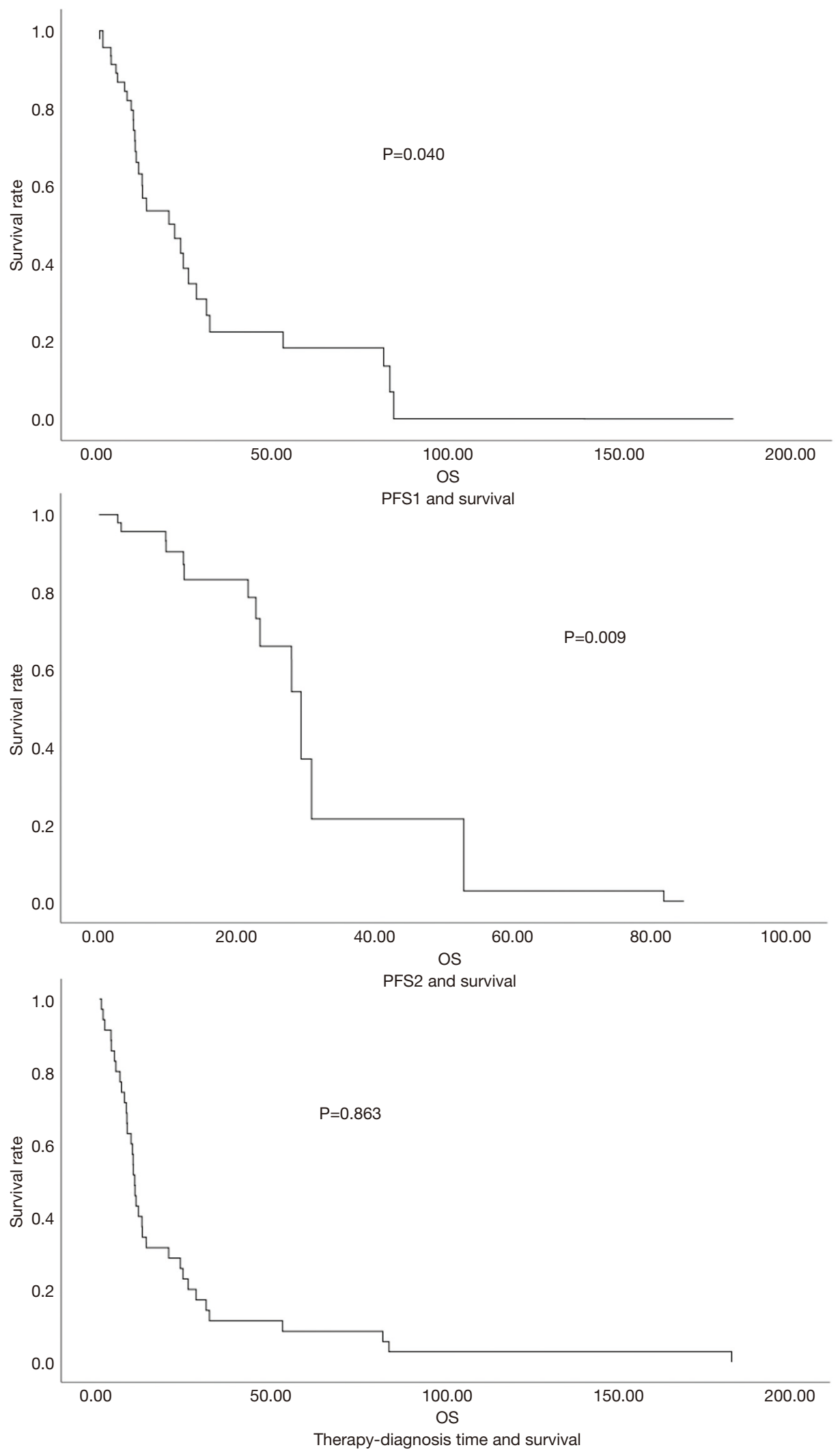

Figure 5 PFS1, PFS2, therapy-diagnosis time, and survival. 
indicate that the treatment of lung cancer in patients aged 80 years and above requires re-evaluation, with multiple factors, in addition to age, needing to be considered for the most effective treatment.

\section{Acknowledgments}

Funding: This work was supported by the Tanslational Medicine Programme of Chinese PLA General Hospital (2017TM-011).

\section{Footnote}

Reporting Checklist: The authors have completed the STROBE reporting checklist. Available at http://dx.doi. org/10.21037/apm-20-2125

Data Sharing Statement: Available at http://dx.doi. org/10.21037/apm-20-2125

Conflicts of Interest: All authors have completed the ICMJE uniform disclosure form (available at http://dx.doi. org/10.21037/apm-20-2125). The authors have no conflicts of interest to declare.

Ethical Statement: The authors are accountable for all aspects of the work in ensuring that questions related to the accuracy or integrity of any part of the work are appropriately investigated and resolved. The study was approved by the PLA General Hospital Medical Ethics Committee (S2020-447-01). All procedures performed in this study involving human participants were in accordance with the Declaration of Helsinki (as revised in 2013). Individual consent for this retrospective analysis was waived.

Open Access Statement: This is an Open Access article distributed in accordance with the Creative Commons Attribution-NonCommercial-NoDerivs 4.0 International License (CC BY-NC-ND 4.0), which permits the noncommercial replication and distribution of the article with the strict proviso that no changes or edits are made and the original work is properly cited (including links to both the formal publication through the relevant DOI and the license). See: https://creativecommons.org/licenses/by-nc-nd/4.0/.

\section{References}

1. Global Burden of Disease Cancer Collaboration,
Fitzmaurice C, Abate D, et al. Global, Regional, and National Cancer Incidence, Mortality, Years of Life Lost, Years Lived With Disability, and Disability-Adjusted LifeYears for 29 Cancer Groups, 1990 to 2017: A Systematic Analysis for the Global Burden of Disease Study. JAMA Oncol 2019;5:1749-68.

2. Zhou M, Wang H, Zeng X, et al. Mortality, morbidity, and risk factors in China and its provinces, 1990-2017: a systematic analysis for the Global Burden of Disease Study 2017. Lancet 2019;394:1145-58.

3. Rami-Porta R, Bolejack V, Giroux DJ, et al. The IASLC lung cancer staging project: the new database to inform the eighth edition of the TNM classification of lung cancer. J Thorac Oncol 2014;9:1618-1624.

4. Yang CJ, Brown AB, Deng JZ, et al. The Oldest Old: A National Analysis of Outcomes for Patients 90 Years or Older With Lung Cancer. Ann Thorac Surg 2020;109:350-7.

5. Nanda RH, Liu Y, Gillespie TW, et al. Stereotactic body radiation therapy versus no treatment for early stage nonsmall cell lung cancer in medically inoperable elderly patients: A National Cancer Data Base analysis. Cancer 2015;121:4222-30.

6. Arnold BN, Thomas DC, Rosen JE, et al. Effectiveness of local therapy for stage I non-small-cell lung cancer in nonagenarians. Surgery 2017;162:640-51.

7. Battisti NML, Sehovic M, Extermann M. Assessment of the External Validity of the National Comprehensive Cancer Network and European Society for Medical Oncology Guidelines for Non-Small-Cell Lung Cancer in a Population of Patients Aged 80 Years and Older. Clin Lung Cancer 2017;18:460-71.

8. Hino H, Karasaki T, Yoshida Y, et al. Risk factors for postoperative complications and long-term survival in lung cancer patients older than 80 years. Eur J Cardiothorac Surg 2018;53:980-6.

9. Muchnik E, Loh KP, Strawderman M, et al. Immune Checkpoint Inhibitors in Real-World Treatment of Older Adults with Non-Small Cell Lung Cancer. J Am Geriatr Soc 2019;67:905-12.

10. clinicaltrials.gov [Internet]. Maryland: U. S. National Library of Mdedicine; c2020 [cited 2020 Nov 9]. Available online: https://clinicaltrials.gov/

11. Ball D, Mai GT, Vinod S, et al. Stereotactic ablative radiotherapy versus standard radiotherapy in stage 1 nonsmall-cell lung cancer (TROG 09.02 CHISEL): a phase 3, open-label, randomised controlled trial. Lancet Oncol 2019;20:494-503. 
12. West H, McCleod M, Hussein M, et al. Atezolizumab in combination with carboplatin plus nab-paclitaxel chemotherapy compared with chemotherapy alone as firstline treatment for metastatic non-squamous non-small-

Cite this article as: Wang $\mathrm{P}, \mathrm{Li} \mathrm{C}$, An Y, Wang X, Liang $\mathrm{Z}$, Chen L. The management of elderly patients with lung cancer: a single center retrospective study. Ann Palliat Med 2021;10(1):229-237. doi: 10.21037/apm-20-2125 cell lung cancer (IMpower130): a multicentre, randomised, open-label, phase 3 trial. Lancet Oncol 2019;20:924-37.

(English Language Editors: E. Tan and J. Gray) 